\title{
Adenoid Cystic Carcinoma of the Lacrimal Gland: A Case Report of Rare Entity
}

\author{
Shaikh $A^{1}$, Bhende ${ }^{1 *}$, Dhondge $R^{2}$, Nagarkar $\mathbf{R}^{3}$, Gandhe $S^{4}$ and Roy $S^{5}$ \\ ${ }^{1}$ Department of Head and Neck Surgical Oncology, Hcg Manavta Cancer Hospital, India \\ ${ }^{2}$ Department of Plastic Surgery, Hcg Manavta Cancer Hospital, India \\ ${ }^{3}$ Chief Surgical Oncologist, Hcg Manavta Cancer Hospital, India \\ ${ }^{4}$ Department of Pathology, Hcg Manavta Cancer Hospital, India \\ ${ }^{5}$ Consultant Surgical Oncologist, Hcg Manavta Cancer Hospital, India
}

Case Report

Volume 6 Issue 1

Received Date: March 18, 2021

Published Date: April 05, 2021

DOI: $10.23880 /$ ooaj-16000209

*Corresponding author: Rajat Bhende, Department of Head and Neck Surgical Oncology, Hcg Manavta Cancer Hospital, Nasik, India, Tel: 09620199292; Email: docrcb@rediffmail.com

\section{Abstract}

Adenoid cystic carcinomas have specific pathologic features that correlate with prognosis. In general, adenoid cystic carcinomas are aggressive tumours with poor prognosis. Treatment most commonly includes surgery with or without radiation and chemotherapy. We describe a patient who presented with right periorbital swelling and CT Face contrast showing well defined soft tissue dense heterogeneously enhancing mass lesion seen along medial wall of right orbital region. The tumour was excised, and pathologic analysis showed an adenoid cystic carcinoma of the lacrimal gland. We review the clinical, radiographic, and pathologic features of these rare malignant tumours as well as treatment options.

Keywords: Adenoid cystic carcinoma; Epithelial tumour; Malignant Tumour; Pathologic analysis

Abbreviations: CT: Computed Tomography; AJCC: American Joint Committee on Cancer.

\section{Introduction}

Adenoid cystic carcinoma is an epithelial tumour seen generally in the major salivary glands, oesophagus, bronchial glands, skin, breast, lungs, vulva, cervix, and prostate. Lorain and Laboulbene originally described adenoid cystic carcinoma in 1853. In 1859, Billroth suggested the name cylindroma. In 1930, Spies suggested the term adenoid cystic carcinoma to replace cylindroma and this terminology has been widely accepted. Until 1940s, the tumour was thought to be of a benign variant of the mixed salivary gland tumour. In 1943, Dockerty and Mayo emphasized the malignant nature of this tumour [1-4]. Adenoid cystic carcinoma is a rare tumour of head and neck region. It accounts for $<1 \%$ of all head and neck malignancies and about $4-10 \%$ of all salivary gland tumours [1,3-7]. Malignant tumours of the lacrimal gland are rare and have an estimated incidence of 0.073 per 100,000 individuals annually. Adenoid cystic carcinomas are the most common type of lacrimal gland malignancy. Patients with adenoid cystic carcinomas may present with asymmetric facial pain or swelling, diplopia, decreased visual acuity, or ptosis. Imaging often shows a nodular, irregular mass that may invade adjacent nerves or bone. Adenoid cystic carcinomas have specific pathologic features that correlate with prognosis. In general, adenoid cystic carcinomas are aggressive tumours with poor prognosis. Treatment most commonly includes surgery with or without radiation and chemotherapy. We describe a patient who presented with right periorbital swelling and CT Face contrast showing well defined soft tissue dense heterogeneously enhancing mass lesion seen along medial wall of right orbital region. The tumour was excised, and pathologic analysis showed an adenoid cystic carcinoma of the lacrimal gland. We review the clinical, radiographic, and pathologic features of these rare malignant tumours as well as treatment options. 


\section{Case Report}

A 38 -year-old female with no past medical history presented with swelling around her right eye that had been progressing over 11 months reported at HCG Manavta Cancer Hospital, (Figure 1) Nasik. She had been experiencing diffuse headaches for past 6 months and excessive lacrimation since 3 weeks before initial presentation. She had intermittent localized pain, No numbness around her eye, weakness on her face, or decreased vision. On examination, the patient had irregular growth on the medial wall of right orbit and non-tender oedema of her Right eyelids and periorbital soft tissue, skin infiltration was seen and epiphora was noted. Visual acuity was 20/20 in both eyes, and visual fields were intact. Her pupils were equally round and reactive, and the fundoscopic examination was unremarkable. She had no demonstrable lymphadenopathy. A computed tomography (CT) scan Face with contrast was done showing well-defined soft tissue dense heterogeneously enhancing mass lesion seen along medial wall of right orbital region. Maximum size of lesion measures $22 \times 16 \times 12 \mathrm{~mm}$ in size. Lesion was abutting the medial aspect of right eye globe with effaced fat plane, medially causing erosion of lamina paparacea. Anteriorly focal infiltration of skin was noted (Figure 2).

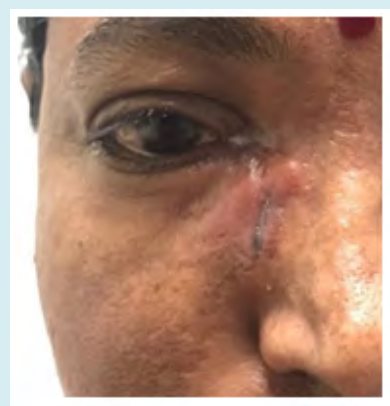

Figure 1: Swelling around right eye.

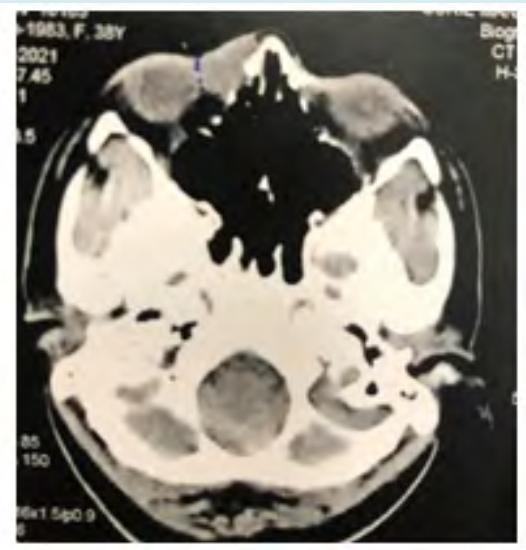

Figure 2: Anteriorly focal infiltration of skin was noted.
The patient underwent right medial wide local excision along right Medial canthal Ligament, lateral nasal wall, infraorbital rim and lateral ethmoidectomy. Reconstruction of the defect was done using free radial artery forearm flap anastomosing with facial artery and facial vein (Figure 3).

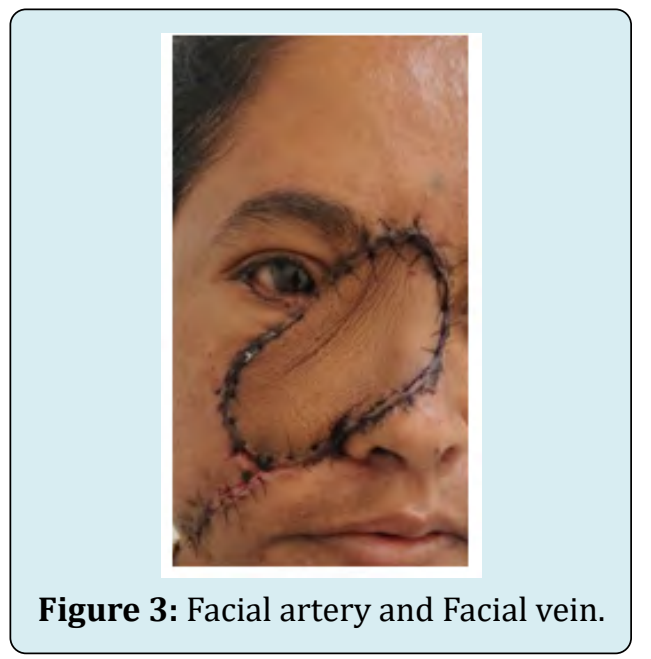

It was noted intraoperatively that all the excised margins sent for frozen section biopsy were free of tumour. Based on the invasion and erosion of nearby bone, the tumour was given a T4 classification. On histologic analysis, the features were containing round, pseudo cystic structures filled with basophilic glycosaminoglycans and eosinophilic, hyalinised basal lamina. Neoplastic cells were predominantly in a cribriform pattern (70\%), and 30\% were in solid sheets. Occasional tubular structures were noted. Smooth muscle actin and CD117 staining identified a predominant myoepithelial cell population suggestive of Adenoid Cystic carcinoma of lacrimal gland (Figure 4), maximum DOI: 1.2 CM, LVE- negative, Extensive PNI- positive, overlying skin is involving tumour, Infraorbital margins free of tumour, pathological staging- T4ANXMX Postoperatively, the patient was referred for radiation therapy. The cribriform growth pattern of his tumour possibly is associated with a better prognosis. However, her overall prognosis was fair, given the tumour's invasion of adjacent bone, positive perineural invasion, and the low survival rate of patients with adenoid cystic carcinoma in general.

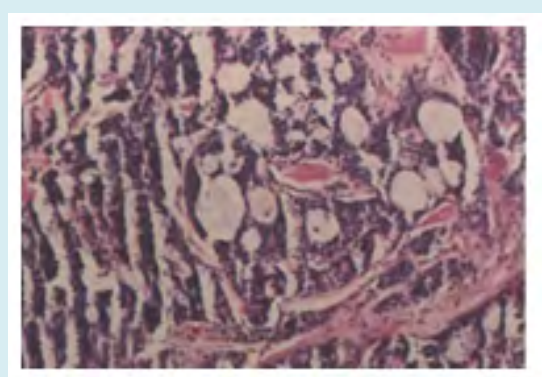

Figure 4: Adenoid Cystic carcinoma of lacrimal gland. 


\section{Otolaryngology Open Access Journal}

\section{Discussion \& Conclusion}

The incidence of lacrimal gland tumours is observed to be less than one per 1,000,000 individuals annually [4]. Patients with lacrimal gland tumours may present with periorbital pain, asymmetric facial swelling, diplopia, vision changes, ptosis, or loss of eye motility [2,3]. Roughly, half of lacrimal gland tumours are malignant [5]. Adenoid cystic carcinoma are the most common type of malignant lacrimal gland tumour; has a peak incidence in the fourth decade; and is a slow growing, aggressive tumour [2,6-8]. Up to $80 \%$ of patients with adenoid cystic carcinomas present with facial pain or numbness secondary to nerve and extraocular muscle invasion [2,5,9]. Metastases are common and can be found in the lungs, liver, bone, brain, and kidney [8]. Although the etiology of adenoid cystic carcinomas is likely multifactorial, the chromosomal translocation (6; 9) (q22-23; p23-24) has been identified in many of the tumours [9-12]. Imaging is useful to distinguish between benign and malignant lacrimal gland tumours and to determine the extent of tumour invasion. On contrast-enhanced CT of the orbits, benign lacrimal gland tumours often appear round and well defined, whereas adenoid cystic carcinomas may appear nodular and irregular [5,13]. Most malignant lacrimal gland tumours also show bone erosion and calcification [5]. Contrast enhanced CT is useful to detect the extent of lacrimal gland tumours; however, MRI is the preferred modality to evaluate for perineural spread and bone invasion [14]. Adenoid cystic carcinomas typically appear T1 isointense and T2 hyperintese with enhancement [5]. Pathologic analysis is needed to differentiate lacrimal gland tumours. Adenoid cystic carcinomas consist of modified myoepithelial and ductal cells that grow in four different patterns: cribriform, basaloid/solid, sclerosing, and tubular [2].

Multiple growth patterns may be seen in a single tumour. Cribriform growth, the most common pattern, is characterized by cyst like structures containing accumulations of basophilic, amorphous glycosaminoglycans or eosinophilic, hyalinized basal lamina. On the other hand, basaloid/solid growth are characterized by a predominance of basaloid myoepithelial cells. The 5-year survival rate of patients with basaloid/solid patterns is $21 \%$ compared with a 5-year survival rate of $71 \%$ in patients with nonbasaloid patterns $[2,7,15]$. In addition, increased numbers of cells expressing tyrosine kinase receptor c-kit (CD117), a protein found in most adenoid cystic carcinomas, is associated with a worse prognosis [5,16]. Given their rarity, there are limited data on the treatment of malignant lacrimal gland tumours. Most agree that initial treatment should include surgery, with or without bone removal or orbitectomy [1719]. Some studies have shown significant benefit to orbital exenteration, whereas others have shown that eye-sparing surgery does not compromise regional or metastatic disease control $[6,20]$. Postoperative radiation therapy may improve outcomes if adequate surgical margins cannot be achieved or if there is intracranial invasion [20,21]. External beam radiotherapy, brachytherapy, stereotactic radiosurgery, and neutron radiotherapy have been used to treat adenoid cystic carcinomas [17,20-27]. One study found that all patients with malignant lacrimal gland tumours who did not receive postoperative radiotherapy developed local or regional recurrence compared with less than $25 \%$ patients who received radiotherapy [20].

Patients with tumours that are difficult to resect may also benefit from neoadjuvant chemotherapy [5,28-30]. Intraarterial platinum-based chemotherapy followed by surgical resection and postoperative radiation has been shown to increase disease free survival and decrease recurrence compared with resection alone [28]. The American Joint Committee on Cancer (AJCC) classification defines a TNM staging system but not a stage grouping for adenoid cystic carcinomas of the lacrimal gland. In the sixth edition of the AJCC Cancer Staging Manual, tumour size was the main determinant of T classification [31]. Some studies have found that patients with tumours $\mathrm{T} 3$ at presentation had shorter overall survival and time to metastasis [6]. In the seventh edition of the AJCC Cancer Staging Manual, tumours of any size are classified as T4 if periosteum or bone is involved [32]. This change in classification has not been shown to correlate with risk of death or time to metastasis for adenoid cystic carcinomas of the lacrimal gland [33]. Overall 10-year of patients diagnosed with adenoid cystic carcinomas is estimated at $20 \%$ to $30 \%$ although some tumours follow a prolonged course [5,33-38]. The recurrence rate of adenoid cystic carcinomas is up to $70 \%[5,6]$. A worse prognosis is associated with neural invasion, basaloid growth pattern, and tumour size $>4 \mathrm{~cm}$ at the time of diagnosis [5].

In summary, we describe a 38-year-old female presenting with right periorbital swelling who was found to have an adenoid cystic carcinoma of the lacrimal gland.

CT face showed classic features of this rare tumour, including irregular margins and bony invasion. Surgical resection, with or without orbitectomy, is recommended in all cases of adenoid cystic carcinomas. Pathologic analysis of our patient's tumour revealed neoplastic cells in a cribriform pattern without perineural or lymphovascular invasion. Our patient has got benefitted from radiation therapy and adjuvant chemotherapy, given the bony invasion by the tumour and positive perineural invasion; however, the overall prognosis is generally poor in patients with adenoid cystic carcinoma. 


\section{Otolaryngology Open Access Journal}

\section{References}

1. Tarpley TM, Giansanti JS (1976) Adenoidcystic carcinoma-analysis of fifty oral cases. Oral Surg Oral Med Oral Pathol 41(4): 484-489.

2. Clark JM, Triana RJ, Meredith SD (2000) Uncontrolled central adenoid cystic carcinoma: Case report. Ear Nose Throat J 79(10): 785-786.

3. Dutta NN, Baruah R, Das L (2002) Adenoidcystic carcinoma-clinical presentation and cytological diagnosis. Indian J Otolaryngol Head Neck Surg 54(1): 62-65.

4. Martínez Rodríguez N, Leco Berrocal I, Rubio Alonso L, Arias Irimia O, Martínez González JM (2011) Epidemiology and treatment of adenoid cystic carcinoma of the minor salivary glands: A meta-analytic study. Med Oral Patol Oral Cir Bucal 16(7): 884-889.

5. Brada M, Henk J (1987) Radiotherapy for lacrimal gland tumours. Radiother Oncol 9(3): 175-183.

6. Schenck NL, Ogura JH, Pratt LL (1973) Cancer of the lacrimal sac: presentation of 5 cases and review of the literature. AnnOtol Rhinol Laryngol 82(2): 153-161.

7. Spaeth EB (1970) A surgical technique for lacrimal sac malignancy. Trans Ophthalmol Soc U K 89: 351-354.

8. Ryan SJ, Font RL (1973) Primary epithelial neoplasms of the lacrimal sac. Am J Ophthalmol 76(1): 73-88.

9. Shields J, Shields C, Freire J, Brady L, Komarnicky L (2003) Plaque radiotherapy for selected orbital malignancies: preliminary observations.The 2002 Montgomery lecture, part 2. Ophthal Plast Reconstr Surg 19(2): 91-95.

10. Douglas JG, Laramore GE, Austin Seymour M, Koh W, Stelzer K, et al. (2000) Treatment of locally advanced adenoid cystic carcinoma of the head and neck with neutron radiotherapy. Int J Radiat Oncol Biol Phys 46(3): 551-557.

11. Kim M, Park K, Kim JH, Kim Y, Lee J (2008) Gamma knife radiosurgery for orbital tumors. Clin Neurol Neurosurg 110(10): 1003-1007.

12. Tse DT, Benedetto P, Dubovy S, Schiffman JC, Feuer WJ (2006)Clinical analysis of the effect of intraarterial cytoreductive chemotherapy in the treatment of lacrimal gland adenoid cystic carcinoma. Am J Ophthalmol 141(1): 44-53.

13. Meel R, Pushker N, Bakhshi S (2009) Adjuvant chemotherapy in lacrimal gland adenoid cystic carcinoma. Pediatr Blood Cancer 53(6): 1163-1164.

14. Meldrum ML, Tse DT, Benedetto P (1998) Neoadjuvant intracarotid chemotherapy for treatment of advanced adenocystic carcinoma of the lacrimal gland. Arch Ophthalmol 116(3): 315-321.

15. Edge SB, Byrd DR, Compton CC, Fritz AG, Greene FL, et al. (2009) AJCC cancer staging manual $7^{\text {th }}$ (Edn.), New York: Springer pp: 569-571.

16. Rootman J, White VA (2009) Changes in the $7^{\text {th }}$ edition of the AJCC TNM classification and recommendations for pathologic analysis of lacrimal gland tumors. Arch Pathol Lab Med 133(8): 1268-1271.

17. El Sawy T, Savar A, Williams MD, De Monte F, Esmaeli B (2012) Prognostic accuracy of the seventh edition vs sixth edition of the American Joint Committee on Cancer tumor classification for adenoid cystic carcinoma of the lacrimal gland. Arch Ophthalmol 130(5): 664-666.

18. Aristodemou P (2010) Lacrimal gland tumor outcomes. Opthalmology 117(1): 196.

19. Kersten RC, Ewing Chow D, Kulwin DR, Gallon M (1997) Accuracy of clinical diagnosis of cutaneous eyelid lesions. Ophthalmology 104(3): 479-484.

20. Mencía Gutierréz E, Guttierréz Diaz E, Ricoy JR, Garcia SM (2001) Primary cutaneous adenoid cystic carcinoma of the eyelid. Am J Ophthalmol 131(2): 281-283.

21. Cooper HC (1987) Carcinomas of sweat glands. Pathol Annu 22(1): 83-124.

22. Murphy GF, Elder DE (1991) Nonmelanocytic tumors of the skin. Atlas of tumor pathology. $3^{\text {rd }}$ series. Fascicle 1, Washington DC: Armed Forces Institute of Pathology, pp: 105.

23. Gamel JW, Font RL (1982) Adenoid cystic carcinoma of the lacrimal gland: the clinical significance of a basaloid histologic pattern. Human Pathol 13(3): 219-225.

24. Zhou Q, Chang H, Zhang H, Han Y, Liu H (2012) Increased numbers of p63-positive/CD117-positive cells in advanced adenoid cystic carcinoma give a poorer prognosis. Diagn Pathol 7: 119.

25. Byers R, Berkeley R, Luna M, Jesse R (1975) Combined therapeutic approach to malignant lacrimal gland tumors. Am J Ophthalmol 79(1): 53-55.

26. Wright JE (1982) Factors affecting the survival of patients with lacrimal gland tumours. Can J Ophthalmol 17(1): $3-9$. 


\section{Otolaryngology Open Access Journal}

27. Wilson KF, Ward DP, Spector ME, Marentette LJ (2011) Orbitocranial approach for treatment of adenoid cystic carcinoma of the lacrimal gland. Ann Otol Rhinol Laryngol 120(6): 397-400.

28. Skinner HD, Garden AS, Rosenthal DI, Ang KK, Morrison WH, et al. (2011) Outcomes of malignant tumors of the lacrimal apparatus: the University of Texas MD Anderson Cancer Center experience. Cancer 117(12): 2801-2810.

29. Von Holstein SL, Coupland SE, Briscoe D, Le Tourneau C, Heegaard S (2013) Epithelial tumours of the lacrimal gland: a clinical, histopathological, surgical and oncologic survey. Acta Ophthalmol 91(3): 195-206.

30. Ahmad SM, Esmaeli B, Williams M, Nguyen J, Fay A, et al. (2009) American Joint Committee on Cancer classification predicts outcome of patients with lacrimal gland adenoid cystic carcinoma. Ophthalmology 116(6): 1210-1215.

31. Bernardini FP, Devoto MH, Croxatto JO (2008) Epithelial tumors of the lacrimal gland: an update. Curr Opin Ophthalmol 19(5): 409-413.

32. Esmaeli B, Ahmadi MA, Youssef A, Diba R, Amato M, et al. (2004) Outcomes in patients with adenoid cystic carcinoma of the lacrimal gland. Ophthal Plast Reconstr Surg 20(1): 22-26.
33. Seethala RR, Cieply K, Barnes EL, Dacic S (2011) Progressive genetic alterations of adenoid cystic carcinoma with high-grade transformation. Arch Pathol Lab Med 135(1): 123-130.

34. Mitani Y, Li J, Rao PH, Zhao YJ, Bell D, et al. (2010) Comprehensive analysis of the MYB-NFIB gene fusion in salivary adenoid cystic carcinoma: incidence, variability, and clinicopathologic significance. Clin Cancer Res 16(19): 4722-4731.

35. Brill LB, Kanner WA, Fehr A, Andren Y, Moskaluk CA, et al. (2011) Analysis of MYB expression and MYB-NFIB gene fusions in adenoid cystic carcinoma and other salivary neoplasms. Mod Pathol 24(9): 1169-1176.

36. West RB, Kong C, Clarke N, Gilks T, Lipsick JS, et al. (2011) MYB expression and translocation in adenoid cystic carcinomas and other salivary gland tumors with clinicopathologic correlation. Am J Surg Pathol 35(1): 92-99.

37. Perez DE, Pires FR, Almeida OP, Kowalski LP (2006) Epithelial lacrimal gland tumors: a clinicopathological study of 18 cases. Otolaryngol Head Neck Surg 134(2): 321-325.

38. Vaidhyanath R, Kirke R, Brown L, Sampath R (2008) Lacrimal fossa lesions: pictorial review of CT and MRI features. Orbit 27(6): 410-418.

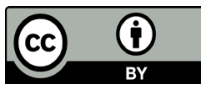

